\title{
LOGISTICS MANAGEMENT AND MARKETING PERFORMANCE OF SMALL AND MEDIUM-SIZED MANUFACTURING FIRMS
}

\author{
Edim Eka James ${ }^{1}$ and Inyang Bassey Inyang ${ }^{2}$ \\ ${ }^{1}$ Department of Marketing, University of Calabar, Nigeria \\ Email: jamesedim@gmail.com (Corresponding author) \\ ${ }^{2}$ Department of Marketing, University of Calabar, Nigeria
}

\section{Cite this article:}

Edim E.J., Inyang B.I. (2022), Logistics Management and Marketing Performance of Small and Medium-Sized Manufacturing Firms. International Journal of Entrepreneurship and Business Innovation 5(1), 115. DOI: 10.52589/IJEBID1D3KF26

\section{Manuscript History}

Received: 4 Jan 2022

Accepted: 29 Jan 2022

Published: 9 Feb 2022

Copyright $\left({ }_{0} 2022\right.$ The Author(s). This is an Open Access article distributed under the terms of Creative Commons AttributionNonCommercial-NoDerivatives 4.0 International (CC BY-NC-ND 4.0 ), which permits anyone to share, use, reproduce and redistribute in any medium, provided the original author and source are credited.

\begin{abstract}
This study explored logistics management and marketing performance of small and medium-sized manufacturing firms. It aimed to assess the influence of order processing, transportation, inventory and warehouse management on the marketing performance of small and medium-sized manufacturing firms. As a cross-sectional study, primary data were obtained from 216 operators and personnel of small and medium-sized manufacturing firms using a structured questionnaire. The research instrument was validated through face and content validity method, while reliability was confirmed through Cronbach's alpha method. The hypotheses developed for the study were tested using multiple linear regression. Consequently, the study revealed that order processing management, transportation management, inventory management and warehouse management had significant positive influences on the marketing performance of small and medium-sized manufacturing firms. Therefore, the study concluded that logistics management has a significant positive influence on marketing performance in the context of small and medium-sized manufacturing firms. Practical implications and a future research agenda were presented in light of the limitations of this study.
\end{abstract}

KEYWORDS: Logistics management, Marketing performance, Small and medium-sized manufacturing firms 


\section{INTRODUCTION}

A country's manufacturing industry is the hub of innovation that creates products and services necessary for economic growth and development, which is why countries around the world are providing increased support to their manufacturing industries as a strategy for enhancing national economic growth (Haraguchi, Cheng \& Smeets, 2017). According to the Bureau of Labour Statistics (2022), the global manufacturing industry accounted for an estimated 12.3 million jobs in the first quarter of 2021, which indicates a 6.34 percent increase in global manufacturing jobs in comparison with the same period in 2020. In China, one of the world's fastest growing economies, the manufacturing industry has been identified as a dominant contributor to increases in Gross Domestic Product in the second quarter of 2021 (Trading Economics, 2021). In Nigeria, the National Bureau of Statistics (NBS) reports that the manufacturing industry contributed to the nation's GDP by 14.18 percent in the second quarter of 2021, which outstripped its contribution of 11.79 percent in the same period of 2020 (Anyalewechi, 2021). This indicates the enormous significance of the manufacturing industry to economic growth. However, the growth of the global manufacturing industry was adversely affected by the outbreak of the COVID-19 pandemic, which triggered scarcities of manufacturing materials, shortages in labour force and skyrocketing energy prices, which in turn undermined the productivity of manufacturing firms around the world (Song \& Zhou, 2020; Zamolo, 2021). As part of the response strategies to the adverse impacts of the pandemic, manufacturing companies sought to optimize their resource utilization through a variety of logistics management practices (Choi, 2021; Montoya-Torres, Muñoz-Villamizar \& MejiaArgueta, 2021).

Logistics management is a subset of supply chain management which is involved in planning, executing and controlling the seamless and timely flow as well as storage of products, services and relevant information from source or origin to the place of consumption in order to satisfy the requirements of customers (Amin \& Shahwan, 2020). As a vital component of supply chain management, manufacturing companies apply various logistics management strategies in the hopes of optimizing organizational performance. Within the scope of this study, the emphasis is on order processing management, transportation management, inventory management and warehouse management. Order processing management is the deliberate process of planning, coordinating and ensuring that customers' orders are effectively elicited, sorted, and delivered to fulfill customers' requirements (Acero, Torralba, Pérez-Moya \& Pozo, 2019). Transportation management involves managing the movement of input materials into a firm as well as the onward movement of finished products and services from the firm to places of consumption in order to satisfy customers' requirements (Speranza, 2018). Kritchanchai and Meesamut (2015) believe that inventory management is the around-the-clock planning, coordinating and control of raw materials, work-in-progress and finished goods to ensure the availability of optimal inventory while guarding against overstocking, understocking and unexpected stock-out. On the other hand, warehouse management is the process of ensuring the availability and functionality of facilities needed to safely, securely and effectively store inventory for future sale or production (Mao, Xing \& Zhang, 2018). Existing studies have shown that manufacturing companies, especially large-sized companies rely on these logistics management strategies in their efforts to enhance organizational performance (Ristovska, Kozuharov \& Petkovski, 2017; Abdul, Iortimbir, Oladipo \& Olota, 2019; Chala, 2021). 
Given the indispensable need to consistently enhance organizational performance in dynamic business environments, researchers have explored studies aimed at determining how logistics management practices could be applied to sustainably enhance organizational performance. However, researchers have often shortchanged and under-prioritized small and medium-sized manufacturing enterprises in their investigations as their overwhelming research attention has been devoted to large-sized manufacturing companies (Ristovska, Kozuharov \& Petkovski, 2017; Abdul, Iortimbir, Oladipo \& Olota, 2019; Chala, 2021; Mwangangi, 2016), construction companies (Eshetu, 2020), humanitarian organizations (Wasike \& Juma, 2020), shipping firms (Kirui \& Nondi, 2017), and gas-processing companies (Takwi \& Mavis, 2020). This entails that there is insufficient empirical evidence to demonstrate the role of logistics management practices in enabling small and medium-sized manufacturing companies to enhance their marketing performance irrespective of the recognized significance of these enterprises to economic development. This study was therefore carried out to critically assess the influence of logistics management (order processing management, transportation management, inventory management and warehouse management) on the marketing performance of small and medium-sized manufacturing firms to determine how these logistics management strategies could effectively be implemented to sustainably enhance the marketing performance of these enterprises.

\section{LITERATURE REVIEW}

\section{Logistics management}

Logistics management is a subset of supply chain management which is involved in planning, executing and controlling the seamless and timely flow as well as storage of products, services and relevant information from source or origin to the place of consumption in order to satisfy the requirements of customers (Amin \& Shahwan, 2020). It is a comprehensive supply-chain function that is concerned with planning, coordinating and overseeing the flow of input materials, market information, products and services from where they originate or are produced to where they are sold and ultimately consumed by customers. In the views of Ristovska, Kozuharov and Petkovski (2017), logistics management can be seen as an element of supply chain management useful in the satisfaction of customers' requirements via the planning, coordination and execution of the flow and storage of vital information, products and services from source of production or supply to point of sale or consumption. This supply-chain function enables business organizations to minimize marketing expenditure while enhancing their ability to provide customer services. Basically, the task of logistics management starts from the acquisition of raw materials and other input materials to the last phase, which is the delivery of finished products and services to the point of consumption (Chala, 2021). While there are various strategies of logistics management, the strategies relevant to this study include order processing management, transportation management, inventory management and warehouse management.

Basically, service quality is the difference obtained from a comparison between customers' perceived anticipations and the actual performance of the service provider or its services. This conceptualization of service quality has its origin in the expectancy-disconfirmation paradigm (Oliver, Balakrishnan \& Barry, 1994). It could be viewed as a customer's perception of the degree to which a delivered service meets or exceeds their expectations from the provider 
(Bitner, 1990; Parasuraman, Berry \& Zeithaml, 1985). Harvey (2015) defines service quality as an assessment of how well a delivered service conforms to the client's expectations. Service quality is the difference between perceived performance and actual performance of service. It is the degree to which actual performance of service meets or exceeds consumers' perceived performance of service (Bryan \& Shales, 2012). Gurley (2018) maintains that ideally, all customers hold certain expectations that they hope to be fulfilled by services consumed even before actually consuming the service. Service quality measures how well a service is delivered compared to customer expectations. Prakash and Mohanty (2012) assert that scholars from across the academic spectrum have contributed to an understanding of service quality, however, with over two decades of study and much lively debate, the conceptual work on service quality can be best described as divergent.

\section{Order processing and marketing performance}

Order processing management is the deliberate process of planning, coordinating and ensuring that customers' orders are effectively elicited, sorted, and delivered to fulfill customers' requirements (Acero, Torralba, Pérez-Moya \& Pozo, 2019). It involves the process of effectively and efficiently monitoring and tracking customers' orders for the purpose of ensuring that they are consistently fulfilled. Typically, an order-processing management process involves eliciting customers' orders, matching them against inventory available, selecting the products ordered, and monitoring them from dispatch point until they arrive at the customer's destination. According to Kirui and Nondi (2017), order processing management involves taking, monitoring and satisfying orders by customers in a timely manner. The task of order processing management starts at the instance a customer places their order and completes at the instance that the customer takes delivery of the product or service as required. Order processing management is an essential aspect of logistics management because it enhances the company's ability to consistently meet and satisfy customers' needs or requirements which is a major determinant of improved marketing performance. This entails that order processing management facilitates improvements in companies' marketing performances. This premise corresponds with the study of Mwangangi (2016), which revealed that order process management significantly influenced the performance of Kenyan manufacturing firms. The premise is also backed by the study of Nyaberi and Mwangangi (2014), which revealed that order processing management contributes substantially to improvement in organizational performance of Rift Valley Bottlers Limited in Kenya. Similarly, the premise is backed by the study of Gitonga (2017), which revealed that order process management had a significant positive influence on operational performance of fastmoving consumer goods manufacturers in Nairobi.

\section{Transportation management and marketing performance}

Transportation is an indispensable aspect of logistics management, in the sense that the logistics management process will completely be in a state of paralysis if its transportation component is undermined (Speranza, 2018). This entails that effective and efficient logistics management operations cannot be achieved without a reliable and functional transportation management system that could easily be activated as and when needed. Transportation management is the process of managing the movement of input materials into a firm as well as the onward movement of finished products and services from the firm to places of consumption in order to satisfy customers' requirements (Speranza, 2018). It involves the physical movement of raw materials, and other input materials to the factory or warehouse to 
facilitate processing or transformation into finished products which are then moved to the point of consumption to satisfy customers' requirements. There are two forms of transportation in logistics management, namely: inbound transportation (involving the movement of raw materials and other input materials from suppliers or origin to the firm for processing and production) and outbound transportation (which involves the movement of finished products and services from firms, factories or warehouses to points of consumption) (Ngamvichaikit, 2017). Transportation management is an essential ingredient required to achieve improved logistics performance and by extension, organizational performance. This premise asserts that marketing performance of companies could be enhanced through transportation management. This premise is consistent with the study of Ristovska, Kozuharov and Petkovski (2017), which revealed that transportation management had a significant positive impact on the performance of Macedonian manufacturing companies. The premise corresponds with the study of Abdul, Iortimbir, Oladipo and Olota (2019), which revealed that transportation management had a significant positive influence on organizational performance of Dangote Flour Mills. Similarly, the premise aligns with the study of Chala (2021), which revealed that transportation management had a significant positive effect on organizational performance in Ethiopia.

\section{Inventory management and marketing performance}

Inventory is the life-blood of any commercial enterprise, because it constitutes the company's value proposition and the means through which customers' needs could be met. This is because inventory comprises all raw materials, productive materials, work-in-progress and finished products of a company at a given period of time (Wild, 2017). Inventory is central to the success of commercial enterprises because it is required for the effective execution of commercial operations necessary for profit maximization, hence the need for inventory to be intently managed by companies. According to Kritchanchai and Meesamut (2015), inventory management is the around-the-clock planning, coordinating and control of raw materials, work-in-progress and finished goods to ensure the availability of optimal inventory while guarding against overstocking, understocking and unexpected stock-out. It comprises initiatives and efforts aimed at planning, coordinating and supervising the availability of inventory as well as their replenishment in the event of a stock-out. Effective inventory management not only saves costs incurable from unnecessary storage as a result of overstocking or loss of customers as a result of stock-out; it also ensures that companies are in a position to consistently supply enough quantities of products required to efficiently meet customers' demands (Mora-Ochomogo, Mora-Vargas \& Serrato, 2016). As such, inventory management possesses the capacity to enhance a company's marketing performance. This assertion finds support in the empirical study of Wasike and Juma (2020), which revealed that inventory management had a significant impact on logistic performance of humanitarian organizations in Kenya. The assertion is also consistent with the study of Gitonga (2017), which revealed that inventory management had a significant positive influence on operational performance of fast-moving consumer goods manufacturers in Nairobi. Similarly, the assertion corresponds with the study of Takwi and Mavis (2020), which revealed that inventory management significantly influenced the performance of Gas Depot Atem in Cameroon.

\section{Warehouse management and marketing performance}

A warehouse is a designated facility and/or structure especially designed to store raw materials, finished products and other product materials for future production or sale (Torabizadeh, Yusof, Ma'aram \& Shaharoun, 2020). It is a specialized facility used by business firms to store 
excess quantities of products, work-in-progress and other accessories to be used in future production or for future sale. Warehouses are fundamental to the operations of manufacturers and business organizations, in general, because they enable the storage of excess commodities, raw materials and finished products in safe and secure facilities for use in a future time period. In doing so, manufacturers can produce in large quantities, while being confident of certain sales opportunities in the nearest future (Faber, De Koster \& Smidts, 2018). Warehouse management is hence the process of ensuring the availability and functionality of facilities needed to safely, securely and effectively store inventory for future sale or production (Mao, Xing \& Zhang, 2018). It involves efforts aimed at ensuring warehouses are sited in the right locations; they are fitted or equipped with the requisite facilities and accessories required for effective storage and that those facilities are consistently maintained to ensure uninterrupted storage operations. By carefully managing warehousing facilities, companies can rest assured that the raw materials and finished products required to meet customers' demands are readily available as and when needed. This entails that warehouse management is central to the improvement of companies' marketing performance. This assertion is consistent with the study of Kirui and Nondi (2017), which revealed that warehousing management had a significant effect on organizational performance of shipping firms in Kenya. The assertion aligns with the study of Wasike and Juma (2020), which revealed that warehouse management had a significant impact on logistic performance of humanitarian organizations in Kenya. Similarly, the assertion is backed by the study of Gitonga (2017), which revealed that warehouse management had a significant positive influence on the operational performance of fastmoving consumer goods manufacturers in Nairobi.

\section{Empirical review and conceptual framework}

Ristovska, Kozuharov and Petkovski (2017) conducted a study to explore the impact of logistics management strategies on the performance of manufacturing companies. The study used a structured questionnaire to elicit primary data from 352 personnel of manufacturing companies in Macedonia. The hypotheses developed for the study were tested using multiple regression analysis. Consequently, the study found that inventory management, storage and warehousing management, transportation management and information management had significant positive impacts on the performance of Macedonian manufacturing companies. Another study conducted by Abdul, Iortimbir, Oladipo and Olota (2019) used a survey questionnaire to obtain primary data from 115 personnel of Dangote Flour Mills in Ilorin. Data analysis was done using Pearson's Product Moment Correlation statistics and regression analysis. The study found that transportation management, information flow management, and inventory management had significant positive influences on organizational performance of Dangote Flour Mills. Similarly, Chala (2021) carried out a study in which a structured questionnaire was used to obtain primary data from 190 factory workers. Data analysis was done using descriptive statistics, Pearson's correlation and multiple regression analysis. The study found that transportation management, inventory management, and warehouse management had significant positive effects on organizational performance in Ethiopia. Another study by Mwangangi (2016) used online surveys and self-administered questionnaires to obtain data from 320 heads of logistics management in selected Kenyan manufacturing firms. Descriptive statistics and multiple regression were adopted for data analysis in the study. The study found that transport management, inventory management, order process management and information flow management significantly influenced the performance of Kenyan manufacturing firms. 
In Kenya, the study of Nyaberi and Mwangangi (2014) obtained primary data from 80 employees of Rift Valley Bottlers Limited in Kenya using questionnaires and personal interviews. The data obtained were analyzed using descriptive statistics. The findings of the study revealed that order processing management, transportation management, inventory management, and information systems management contribute substantially to improvement in organizational performance of Rift Valley Bottlers Limited in Kenya. Also, Eshetu (2020) used a structured questionnaire to collect data from 53 logistics department personnel of Elmi Olindo Contractors Plc, Addis Ababa. Descriptive statistics and Pearson's correlation analysis were the statistical tools adopted for data analysis and hypothesis testing in the study. The study found that transportation management, customer service management, inventory management, supply management, and warehouse management had significant positive relationships with organizational performance of construction firms. Similarly, a Kenyan study by Kirui and Nondi (2017) obtained primary data from personnel of 16 shipping lines in Mombasa County using a structured questionnaire. Descriptive statistics were used for data analysis while multiple regression analysis was used for hypothesis testing. The findings revealed that warehousing management, inventory management and transportation management had significant effects on organizational performance of shipping firms in Kenya. Another Kenyan study by Wasike and Juma (2020) elicited primary data from 64 personnel of humanitarian organizations in Kenya using a semi-structured questionnaire. In the study, data analysis was carried out using descriptive and regression analysis. The study found that inventory management, transportation management, information flow management and warehouse management had significant impacts on logistic performance of humanitarian organizations in Kenya.

Furthermore, in the study by Gitonga (2017), primary data were obtained from 85 personnel of fast-moving manufacturing companies in Kenya using a self-administered questionnaire. Data analysis was carried out using descriptive statistics and multiple regression analysis. The study found that order process management, inventory management, transportation management, information flow management, warehouse management and packaging practices had significant positive influences on operational performance of fast-moving consumer goods manufacturers in Nairobi. Also, Takwi and Mavis (2020) examined logistics management and organizational performance by obtaining primary data from 40 personnel of Gas Depot Atem in Yaounde using a semi-structured questionnaire while data analysis was carried out using simple regression. The findings of the study revealed that transport management, inventory management, order process management and information flow management significantly influenced the performance of Gas Depot Atem in Cameroon. In addition, Mukolwe and Wanyoike (2015) carried out a study which obtained primary data from 92 personnel of Mumias Sugar Company, farmers and officials of the Kenyan Ministry of Agriculture using a structured questionnaire and personal interviews. The obtained data in the study were analyzed using descriptive statistics, Pearson's correlation and regression analysis. The study found that information flow management, warehouse automation, transportation management and physical distribution practices had significant positive effects on operational efficiency of Mumias Sugar Company Limited, Kenya.

Informed by a review of existing literature, this study adopted order processing management, transportation management, inventory management and warehouse management as proxies of logistics management, while marketing performance was measured through proxies such as customer satisfaction, customer retention and sales growth. In light of existing empirical 
evidence by previous researchers, this study hypothesized that logistics management practices are related with the marketing performance of small and medium-sized manufacturing firms. To demonstrate the hypothesized relationship between the study variables, a conceptual model in Fig. 1 was adapted from existing studies to suit the context of the present study.

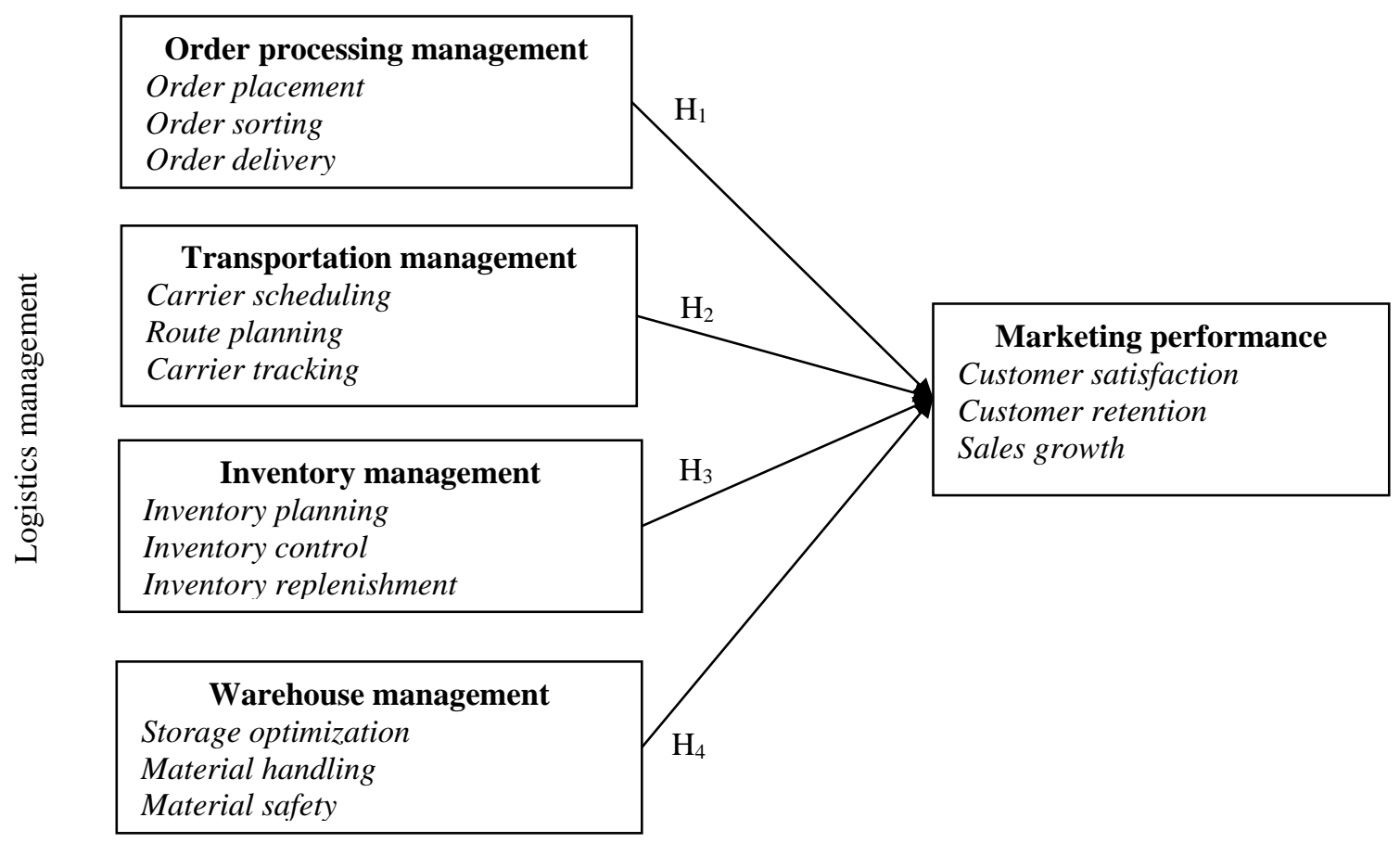

Fig. 1: Adapted conceptual model for the study

Source: Proxies of independent variable adapted from Kirui and Nondi (2017); Wasike and Juma (2020). Proxies of dependent variable adapted from Ambler, Kokkinaki and Puntoni (2004)

\section{METHODOLOGY}

This study utilized cross-sectional survey research design, whereby respondents were surveyed to obtain data for the study at one single point in time, to assess the current status of the relationship between logistics management and marketing performance in the context of small and medium-sized manufacturing firms. The target population comprised operators and personnel of small and medium-sized manufacturing firms in Calabar Metropolis, Nigeria. Using the Topman size determination method for infinite populations (Hilda \& Audu, 2021), a sample size of 248 operators and personnel of small and medium-sized manufacturing firms was statistically determined for the study. Cluster random sampling was used to select small and medium-sized manufacturing firms in Calabar South and Municipality to participate in the study. With the aid of a 3-member team of enumerators, the study administered a structured questionnaire to respondents to obtain the data required. The research questionnaire had a 5point Likert scale design with statements adapted from Kirui and Nondi (2017); Wasike and 
Juma (2020); and Ambler, Kokkinaki and Puntoni (2004), to measure the study variables (order processing, transportation, inventory, and warehouse management). Face and content validity methods were adopted to validate the questionnaire while Cronbach's alpha coefficients confirmed the instrument's reliability prior to field administration. The instrument was considered reliable because all its measurement scales generated Cronbach's alpha coefficients ranging from 0.7 and above: Order processing management $[\alpha=0.711]$; transportation management $[\alpha=0.775]$; inventory management $[\alpha=0.800]$; warehouse management $[\alpha=$ $0.704]$; and marketing performance [ $\alpha=0.751]$. Subsequently, the hypotheses developed for this study were statistically tested and validated using multiple linear regression with the following regression model:

$\mathrm{MKTPERF}=\mathrm{a}+\beta_{1} \mathrm{OPM}+\beta_{2} \mathrm{TM}+\beta_{3} \mathrm{IM}+\beta_{4} \mathrm{WM}+\mathrm{e}$

Where:

$\begin{array}{ll}\mathrm{a}= & \text { The intercept }(\text { or constant }) \\ \beta_{1} \mathrm{OPM}= & \text { Coefficient of order processing management } \\ \beta_{2} \mathrm{TM}= & \text { Coefficient of transportation management } \\ \beta_{3} \mathrm{IM}= & \text { Coefficient of inventory management } \\ \beta_{4} \mathrm{WM}= & \text { Coefficient of warehouse management } \\ \mathrm{e}= & \text { Error margin }(5 \text { percent })\end{array}$

\section{ANALYSIS AND DISCUSSION}

To obtain data for the study, a total of 248 questionnaire copies were administered to operators and personnel of small and medium-sized manufacturing firms; however, 216 copies (representing 87.1 percent) were retrieved and considered usable for analysis, while the remaining 32 copies (representing 12.9 percent) were technically unusable for the study.

Following a multivariate analytical procedure, the hypotheses developed for the study were tested as follows:

(i) $\mathbf{H}_{\mathbf{0}}$ : Order processing management has no significant effect on the marketing performance of small and medium-sized manufacturing firms.

(ii) $\mathbf{H}_{\mathbf{0}}$ : Transportation management has no significant effect on the marketing performance of small and medium-sized manufacturing firms.

(iii) $\mathbf{H}_{\mathbf{0}}$ : Inventory management has no significant effect on the marketing performance of small and medium-sized manufacturing firms.

(iv) $\mathbf{H}_{\mathbf{0}}$ : Warehouse management has no significant effect on the marketing performance of small and medium-sized manufacturing firms. 
International Journal of Entrepreneurship and Business Innovation

ISSN: 2689-9493

Volume 5, Issue 1, 2022 (pp. 1-15)

www.abjournals.org

Predictors: Order processing management, transportation management, inventory management and warehouse management

Outcome: Marketing performance

Decision rule: Reject the null hypothesis $\left(\mathrm{H}_{\mathrm{o}}\right)$ if the $\mathrm{P}$-value is less than 0.05 (i.e., $\mathrm{p}<.05$ ); accept the null hypothesis if $\mathrm{P}$-value is greater than 0.05 (i.e., $\mathrm{p}>.05$ )

Table 1: Model summary of the effect of logistics management and marketing performance of small and medium-sized manufacturing firms

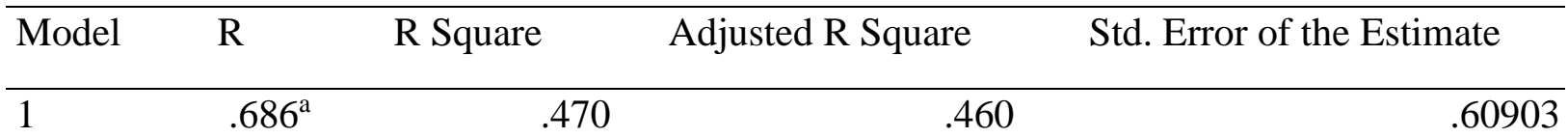

a. Predictors: (Constant), Order processing management, transportation management, inventory management and warehouse management

Source: Authors' calculations via SPSS (2021)

Table 2: ANOVA ${ }^{\mathrm{a}}$ of the effect of logistics management and marketing performance of small and medium-sized manufacturing firms

\begin{tabular}{|c|c|c|c|c|c|c|}
\hline \multicolumn{2}{|c|}{ Model } & Sum of Squares & Df & Mean Square & $\mathrm{F}$ & Sig. \\
\hline \multirow[t]{3}{*}{1} & Regression & 69.440 & 4 & 17.360 & 46.802 & $.000^{\mathrm{b}}$ \\
\hline & Residual & 78.264 & 211 & .371 & & \\
\hline & Total & 147.704 & 215 & & & \\
\hline
\end{tabular}

a. Dependent Variable: Marketing performance

b. Predictors: (Constant), Order processing management, transportation management, inventory management and warehouse management

Source: Authors' calculations via SPSS (2021)

Table 3: Coefficients of the effect of logistics management and marketing performance of small and medium-sized manufacturing firms

\begin{tabular}{|c|c|c|c|c|c|}
\hline \multirow[b]{2}{*}{ Model } & \multicolumn{2}{|c|}{$\begin{array}{l}\text { Unstandardized } \\
\text { Coefficients }\end{array}$} & \multirow{2}{*}{$\begin{array}{c}\text { Standardized } \\
\text { Coefficients } \\
\text { Beta } \\
\end{array}$} & \multirow[b]{2}{*}{$\mathrm{t}$} & \multirow[b]{2}{*}{ Sig. } \\
\hline & $\mathrm{B}$ & Std. Error & & & \\
\hline $1 \quad$ (Constant) & .700 & .311 & & 12.255 & .025 \\
\hline $\begin{array}{l}\text { Order processing } \\
\text { management }\end{array}$ & .118 & .063 & .507 & 7.869 & .000 \\
\hline Transportation management & .048 & .072 & .343 & 9.663 & .008 \\
\hline Inventory management & -.132 & .056 & .637 & 2.349 & .020 \\
\hline Warehouse management & .869 & .079 & .584 & 11.024 & .000 \\
\hline
\end{tabular}

a. Dependent Variable: Marketing performance

Source: Authors' calculations via SPSS (2021) 


\section{Interpretation}

The results displayed in Tables 1-3 depict the multiple regression analysis of the effect of logistics management and marketing performance of small and medium-sized manufacturing firms. The correlation coefficient $(\mathrm{R}=0.686)$ in Table 1 indicates that logistics management has a very high degree of relationship of up to 68.6 percent with the marketing performance of small and medium-sized manufacturing firms. The regression coefficient of determination $\left(\mathrm{R}^{2}\right.$ $=0.470$ ) indicates that about 47.0 percent of the variation in the marketing performance of small and medium-sized manufacturing firms is predicted by logistics management. The Fstatistic $(F=46.802)$ and significance level (sig. $=0.000<.05)$ in Table 2 indicate that the regression model is statistically significant, thereby implying that the effect of logistics management on the marketing performance of small and medium-sized manufacturing firms is significant. Furthermore, given that the p-values of all the predictor variables tested were below the error margin of 0.05 with positive $t$-values [order processing management ( $\mathrm{p}$-value $=0.000 ; \mathrm{t}$-value $=7.869) ;$ transportation management $(\mathrm{p}$-value $=0.008 ; \mathrm{t}$-value $=9.663)$; inventory management $(\mathrm{p}$-value $=0.020 ; \mathrm{t}$-value $=2.349)$ and warehouse management $(\mathrm{p}$ value $=0.000 ; \mathrm{t}$-value $=11.024)$, this provides credible statistical evidence to conclude that order processing management, transportation management, inventory management and warehouse management have significant positive influences on the marketing performance of small and medium-sized manufacturing firms. However, considering each variable's standardized Beta coefficients displayed in Table 3, it can be seen that the variable with the highest significant influence on the marketing performance of small and medium-sized manufacturing firms is inventory management $(\beta=0.637$ or 63.7 percent). Warehouse management had the second-highest significant influence on marketing performance $(\beta=$ 0.584 or 58.4 percent), while order processing management had the third-highest significant influence on marketing performance ( $\beta=0.507$ or 50.7 percent). Transportation management had the least significant influence on marketing performance of small and medium-sized manufacturing firms $(\beta=0.343$ or 34.3 percent $)$.

\section{DISCUSSION OF FINDINGS}

The first finding of the study revealed that order processing management had a significant positive influence on the marketing performance of small and medium-sized manufacturing firms. This finding is consistent with the study of Mwangangi (2016), which revealed that order process management significantly influenced the performance of Kenyan manufacturing firms. The finding is also backed by the study of Nyaberi and Mwangangi (2014), which revealed that order processing management contributes substantially to improvement in organizational performance of Rift Valley Bottlers Limited in Kenya. Also, the finding is backed by the study of Gitonga (2017), which revealed that order process management had a significant positive influence on operational performance of fast-moving consumer goods manufacturers in Nairobi. The implication of this finding is that like large-sized manufacturing companies, small and medium-sized manufacturers can substantially enhance their marketing performance by engaging in effective and efficient order processing management practices such as order placement, order sorting and order delivery management. 
The second finding of the study indicates that transportation management had a significant positive influence on the marketing performance of small and medium-sized manufacturing firms. This finding is consistent with the study of Ristovska, Kozuharov and Petkovski (2017), which revealed that transportation management had a significant positive impact on the performance of Macedonian manufacturing companies. The finding corresponds with the study of Abdul, Iortimbir, Oladipo and Olota (2019), which revealed that transportation management had a significant positive influence on organizational performance of Dangote Flour Mills. Similarly, the finding aligns with the study of Chala (2021), which revealed that transportation management had a significant positive effect on organizational performance in Ethiopia. This finding implies that as is the case with large-sized manufacturing firms, small and medium-sized manufacturing firms can substantially improve their marketing performance by engaging in transportation management practices such as carrier scheduling, route planning and carrier tracking.

Furthermore, the third finding revealed that inventory management had a significant positive influence on the marketing performance of small and medium-sized manufacturing firms. This finding is supported by the study of Wasike and Juma (2020), which revealed that inventory management had a significant impact on logistic performance of humanitarian organizations in Kenya. The finding is also consistent with the study of Gitonga (2017), which revealed that inventory management had a significant positive influence on operational performance of fastmoving consumer goods manufacturers in Nairobi. Similarly, the finding corresponds with the study of Takwi and Mavis (2020), which revealed that inventory management significantly influenced the performance of Gas Depot Atem in Cameroon. The implication of this finding is that like large-sized manufacturing companies, small and medium-sized manufacturing companies could achieve improvements in their marketing performance by engaging in inventory management practices such as inventory planning, inventory control and inventory replenishment.

Finally, the fourth finding of the study revealed that warehouse management had a significant positive influence on the marketing performance of small and medium-sized manufacturing firms. This finding is consistent with the study of Kirui and Nondi (2017), which revealed that warehousing management had a significant effect on organizational performance of shipping firms in Kenya. The finding also aligns with the study of Wasike and Juma (2020), which revealed that warehouse management had a significant impact on logistic performance of humanitarian organizations in Kenya. Similarly, the finding is backed by the study of Gitonga (2017), which revealed that warehouse management had a significant positive influence on operational performance of fast-moving consumer goods manufacturers in Nairobi. The implication of this finding is that as is the case with large-sized manufacturing firms, small and medium-sized manufacturers could substantially improve their marketing performance by applying warehouse management practices such as storage utilization, material handling and material safety. 


\section{CONCLUSION AND PRACTICAL IMPLICATIONS}

Against the backdrop of the unavailability of sufficient empirical evidence to demonstrate the role of logistics management practices in enhancing the performance of small and mediumsized manufacturing companies, this study was carried out to critically assess the influence of logistics management (order processing management, transportation management, inventory management and warehouse management) on the marketing performance of small and medium-sized manufacturing firms to determine how these logistics management strategies could effectively be implemented to sustainably enhance the marketing performance of these enterprises. To that end, the study elicited primary data from operators and personnel of small and medium-sized manufacturing firms using a structured questionnaire. Through multivariate analysis of the data obtained for the study, it was found that order processing management, transportation management, inventory management and warehouse management had significant positive influences on the marketing performance of small and medium-sized manufacturing firms. The implication of these findings is that by applying effective logistics management practices (such as order processing, transportation, inventory and warehouse management), small and medium-sized manufacturing firms can substantially enhance their marketing performance just like their large-scale counterparts. Therefore, the study concludes that logistics management has a significant positive influence on marketing performance in the context of small and medium-sized manufacturing firms.

Consequently, for small and medium-sized manufacturing firms to make the most of logistics management in their operations, it is essential that they monitor their order placement, order sorting and order delivery processes to ensure that customers' orders are satisfactorily fulfilled at the right time. Small and medium-sized manufacturing firms should also prioritize transportation management by carefully coordinating their carrier scheduling, route planning and carrier tracking processes to ensure that in-bound and out-bound transportation of products and productive materials flow seamlessly as required. Given that inventory management has been confirmed in this study to have the most influence on the performance of small and medium-sized manufacturing firms, it is imperative for these firms to critically coordinate and execute inventory planning, inventory control and inventory replenishment in order to ensure the availability of inventory required for production and customer service. Finally, the relevance of warehouse management to the performance of small and medium-sized manufacturing firms cannot be overemphasized; hence these firms should ensure the availability and functionality of modernized facilities for material and/or product storage, handling and preservation.

\section{Limitations and Future Research}

The data used in this study was obtained from small and medium-sized manufacturing firms in Nigeria; hence it may not adequately explain the realities of small and medium-sized manufacturing firms in other African and Western countries. There is therefore a need for this study to be replicated in other African as well as Western countries to provide a comprehensive view of the role of logistics management in improving the marketing performance of small and medium-sized manufacturing firms in particular. Based on the researchers' conceptualization, this study centered on four (4) logistics management practices, namely: order processing, transportation, inventory and warehouse management. As such, it cannot sufficiently provide empirical evidence to explain the influence of other logistics management practices on the marketing performance of small and medium-sized manufacturing firms. Therefore, future 
researchers should explore the influence of other logistics management practices such as information flow management, customer service management and logistics automation on the performance of small and medium-sized manufacturing firms in order to add to existing knowledge and empirical evidence.

\section{REFERENCES}

Abdul, F. A., Iortimbir, A. I., Oladipo, G. T. \& Olota, O. O. (2019). Impact of logistics management on organizational performance (A case study of Dangote Flour Mills Plc, Nigeria). Journal of Sustainable Development in Africa, 21(1), 36-49

Acero, R., Torralba, M., Pérez-Moya, R., \& Pozo, J. A. (2019). Order processing improvement in military logistics by Value Stream Analysis lean methodology. Procedia Manufacturing, 41, 74-81.

Ambler, T., Kokkinaki, F., \& Puntoni, S. (2004). Assessing marketing performance: Reasons for metrics selection. Journal of Marketing Management, 20(3-4), 475-498.

Amin, H. M., \& Shahwan, T. M. (2020). Logistics management requirements and logistics performance efficiency: The role of logistics management practices-evidence from Egypt. International Journal of Logistics Systems and Management, 35(1), 1-27.

Anyalewechi, C. (2021). Nigeria's manufacturing sector records real GDP growth of $3.49 \%$ in Q2 2021. Available at: https://nairametrics.com/2021/08/26/nigerias-manufacturingsector-records-real-gdp-growth-of-3-49-in-q2-2021/ (Accessed: January 3, 2022)

Bureau of Labour Statistics (2022). Manufacturing. Available at: https://www.bls.gov/data/\#employment (Accessed: January 3, 2022)

Chala, G. (2021). The effect of logistics management on organizational performance at Wonji/Shoa Sugar Factory. Global Scientific Journals, 9(5), 1962- 1974

Choi, T. M. (2021). Risk analysis in logistics systems: A research agenda during and after the COVID-19 pandemic. Transportation Research Part E: Logistics and Transportation Review, 145, 102190.

Eshetu, D. (2020). The effect of logistics management on organizational performance in construction industries: The case of Elmi Olindo Contractors Plc [Master's Thesis, Addis Ababa University, Ethiopia]

Faber, N., De Koster, R. B., \& Smidts, A. (2018). Survival of the fittest: the impact of fit between warehouse management structure and warehouse context on warehouse performance. International Journal of Production Research, 56(1-2), 120-139.

Gitonga, S. (2017). Logistics management practices and operational performance of fastmoving consumer goods manufacturers in Nairobi [MBA Thesis, University of Nairobi, Kenya]

Haraguchi, N., Cheng, C. F. \& Smeets, E. (2017). The importance of manufacturing in economic development: Has this changed? World Development, 93, 293-315.

Kirui, M. T. \& Nondi, R. (2017). effects of logistics management on the organizational performance of shipping firms in Mombasa County. Strategic Journal of Business \& Change Management, 4(3), 821 - 839

Kritchanchai, D., \& Meesamut, W. (2015). Developing inventory management in hospitals. International Journal of Supply Chain Management, 4(2), 11-19.

Mao, J., Xing, H., \& Zhang, X. (2018). Design of an intelligent warehouse management system. Wireless Personal Communications, 102(2), 1355-1367. 
Montoya-Torres, J. R., Muñoz-Villamizar, A., \& Mejia-Argueta, C. (2021). Mapping research in logistics and supply chain management during COVID-19 pandemic. International Journal of Logistics Research and Applications, 1-21.

Mora-Ochomogo, E. I., Mora-Vargas, J., \& Serrato, M. (2016). A qualitative analysis of inventory management strategies in humanitarian logistics operations. International Journal of Combinatorial Optimization Problems and Informatics, 7(1), 40-53.

Mukolwe, G. A. \& Wanyoike, D. M. (2015). An assessment of the effect of logistics management practices on operational efficiency at Mumias Sugar Company Limited, Kenya. International Journal of Economics, Commerce and Management, 3(6), 11341156

Mwangangi, P. W. (2016). Influence of logistics management on performance of manufacturing firms in Kenya [PhD Thesis, Jomo Kenyatta University of Agriculture and Technology, Kenya]

Ngamvichaikit, A. (2017). The competency development of multimodal transportation management for logistics professionals in Thailand. International Journal of Trade, Economics and Finance, 8(1), 88-103.

Nyaberi, J. N. \& Mwangangi, P. (2014). Effects of logistics management practices on organization performance in Kenya: A case of Rift Valley Bottlers Limited in Uasingishu County. International Journal of Social Sciences and Entrepreneurship, 1(12), 458-473.

Ristovska, N., Kozuharov, S. \& Petkovski, V. (2017). The Impact of logistics management practices on company's performance. International Journal of Academic Research in Accounting, Finance and Management Sciences, 7(1), 245-252

Song, L., \& Zhou, Y. (2020). The COVID-19 pandemic and its impact on the global economy: What does it take to turn crisis into opportunity? China \& World Economy, 28(4), 1-25.

Speranza, M. G. (2018). Trends in transportation and logistics. European Journal of Operational Research, 264(3), 830-836.

Takwi, F. M. \& Mavis, A. A. (2020). The effects of logistic management on enterprise performance: A case of Gas Depot Atem in Yaounde, Cameroon. American Journal of Operations Management and Information Systems.5(3), 41-48

Torabizadeh, M., Yusof, N. M., Ma'aram, A., \& Shaharoun, A. M. (2020). Identifying sustainable warehouse management system indicators and proposing new weighting methods. Journal of Cleaner Production, 248, 119190.

Trading Economics (2021). China GDP from industry. Available at: https://tradingeconomics.com/china/gdp-from-manufacturing (Accessed: January 3, 2022)

Wasike, E. R. \& Juma, D. (2020). Influence of logistics management practices on the logistic performance of humanitarian organizations in Kakamega County, Kenya. International Journal of Scientific and Research Publications, 10(9), 97-109

Wild, T. (2017). Best practice in inventory management. Routledge.

Zamolo, A. (2021). Top 7 manufacturing trends for 2022. Available at: https://www.beekeeper.io/blog/manufacturing-trends/ (Accessed: January 3, 2022) 